\title{
Anti-hyperlipidemic and anti-atherosclerotic effects of Pinus eldarica Medw. nut in hypercholesterolemic rabbits
}

Hasan Fallah Huseini ${ }^{1}$, Maryam Sotoudeh Anvari ${ }^{2}$, Yaser Tajallizadeh khoob ${ }^{3}$, Shahram Rabbani ${ }^{4}$, Farshad Sharifi, Seyed Masoud Arzaghi ${ }^{5}$ and Hossein Fakhrzadeh ${ }^{5^{*}}$

\begin{abstract}
Background: Previous studies suggest that chemical constituents present in Pinus eldarica Medw (P. eldarica) nut possess antioxidant properties that may positively influence lipid profile.

The present study was conducted to evaluate the efficacy of $P$. eldarica nut on the experimental atherosclerosis development in hypercholesterolemic rabbits.

Methods: Forty male 6 months old white New Zealand rabbits $(1.8-2 \mathrm{~kg})$ were randomly assigned into five equal groups. One group was kept as control (normal) group, fed on standard rabbit diet and other 4 groups were fed on high cholesterol diet (HCD). Out of four HCD groups one group was kept as control (HCD) and other three groups were treated with different doses (50, 100 and $200 \mathrm{mg} / \mathrm{kg} /$ day) of P. eldarica nut for 8 weeks. Percentage of aortic wall area changes as indication of atherosclerosis development and fasting blood cholesterol, LDL, HDL and triglyceride levels were determined in all groups.

Results: The results indicate that fasting blood cholesterol and aortic atherosclerotic involvements in $200 \mathrm{mg} / \mathrm{kg} /$ day and $100 \mathrm{mg} / \mathrm{kg} /$ day P. eldarica nut extract treated groups significantly decreased as compared to the high cholesterol-diet control group.
\end{abstract}

Conclusion: $P$. eldarica nut lowers blood cholesterol level and aortic atherosclerotic involvement in hypercholesterolemic rabbits.

Keywords: Pinus eldarica nut, Rabbits, Atherosclerosis, Hypercholesterolemia

\section{Introduction}

Atherosclerotic vascular disease is a major cause of morbidity and mortality worldwide [1]. Dyslipidemia is a crucial risk factor for atherosclerosis and oxidative stress following free radical-mediated oxidation of low-density lipoproteins is associated with progression of atherogenesis and its vascular complications [2-4]. In the search for plant foods that provide cardiovascular benefits, nuts have recently enticed attention. Among nuts, the Iranian pine, Pinus eldarica Medw (P. eldarica) nuts are used as food. $P$. eldarica belongs to the botanical family pinaceae

\footnotetext{
* Correspondence: Fakhrzad@tums.ac.ir

${ }^{5}$ Elderly Health Research Center, Endocrinology and Metabolism Population Sciences Institute, Tehran University of Medical Sciences, 4th floor, No 4, Ostad Nejatollahi Street, Engelab Avenue, Tehran, Iran

Full list of author information is available at the end of the article
}

and naturally grows in the Transcaucasian region between Europe and Asia, and it is also spread in Iran, Afghanistan and Pakistan [5, 6].

In Russia and the Central Asian countries the P. eldarica needles, buds, resin and nuts have been widely used in traditional medicine for the treatment of bronchial asthma, and various skin diseases $[7,8]$. Several components such as $\beta$-caryophyllene, $\alpha$-pinene, longifolene, $\alpha$-humulene, $\delta$-3-carene and $\beta$-pinene with antioxidant properties have been reported in the P. eldarica nut oil [9].

In our previous study high concentrations of total polyphenols and fatty acids have been detected in $P$. eldarica nut as indication of its antioxidant properties [10]. Experimental studies strongly support the efficacy of polyphenols and unsaturated fatty acids in the treatment of chronic diseases including cardiovascular disorders 
[11-14]. The present study was conducted to evaluate the possible anti-hypercholesterolemic and anti-atherosclerotic effects of $P$. eldarica nut in hypercholesterolemic rabbits.

\section{Methods \\ Chemicals}

Methanol, phosphoric acid, chloroform, acetonitril and sodium chloride were purchased from Merck Company (India) nn. Ethyl acetate was purchased from Sinopharm Chemical Reagent Company (China). Polyphenol standards: $(+)$ - catechin, (-) - epicatechin, Gallic acid, vanillic acid, para coumaric acid, ferullic acid, ortho coumaric acid and tyrosol were purchased from Sigma-Aldrich Corporation (Germany). Cholesterol powder was purchased from Solvay Duphar Co., Belgium.

\section{Plant material}

P. eldarica cones were collected from Chitgar Forest Park (West of Tehran). The cones were collected between June and July of 2010. The plant was identified by M. Ahvazi and herbarium specimen was preserved in the herbarium of Medicinal Plants Institute (ACECR) with Herbarium code of 689. P. eldarica cones were dried in a dark place at room temperature. The nuts were removed from cones and grounded to powder by grinder.

\section{Plant extract}

The hydroalcholic extract of $P$. eldarica nut powder was prepared using $70 \%$ ethanol in water, using percolation method at room temperature. The powdered plant material was soaked initially in a solvent in a percolator and then sufficient amount of the solvent was added to cover material and kept for $24 \mathrm{~h}$ with occasional stirring. Then the outlet of the percolator was opened and the liquid contained therein was allowed to drip slowly. The procedure was repeated twice and the combined extractions were clarified by filtration and concentrated to dryness on rotary evaporator at a maximum of $40{ }^{\circ} \mathrm{C}$ temperature and under reduced pressure.

\section{Polyphenol determination}

The polyphenol content of $P$. eldarica nut was determined by the High-performance liquid chromatography (HPLC) method developed by Dogan et al. [15]. In brief a standard solution was prepared by dissolving $10 \mathrm{mg}$ of (+) catechin (sigma), epicatechin (sigma), and other phenolic compounds in $10 \mathrm{ml}$ methanol and diluting this solution with methanol HPLC grade. The range of concentration was between 50 and $1000 \mu \mathrm{g} / \mathrm{ml}$ and standard curve was linear $\left(R^{2} \geq 0.998\right)$. Then $20 \mu \mathrm{L}$ of sample solution was injected to the HPLC and the chromatogram was recorded at $280 \mathrm{~nm}$. First, $20 \mu \mathrm{l}$ of standard solution was injected and the chromatogram was recorded at $280 \mathrm{~nm}$. Next, we compared the area of the peaks in standard and sample chromatograms and calculated the amount of polyphenols in P. eldarica. Total phenol was computed from measurement of individually detected phenols [16].

\section{Animals and diet}

Forty male 6-month-old white New Zealand rabbits $(1.8-2 \mathrm{~kg})$ were purchased from Razi Research Institute, Karaj, Iran. High cholesterol diet (HCD) was prepared by adding of $1 \mathrm{~g}$ cholesterol powder and $3 \mathrm{~g}$ corn oil to $96 \mathrm{~g}$ of standard laboratory food.

\section{General procedures}

Rabbits were housed individually in cages in temperaturecontrolled room $\left(24{ }^{\circ} \mathrm{C}\right)$ under a 12-h light/dark cycle with free access to food and water in the Animal Research Center of Institute of Medicinal Plants. The experimental protocol was approved by the Iranian Institutional Animal Ethics Committee and was conducted according to the Iranian Institutional Animal Care Guidelines for the use and care of experimental animal, drug, dose, and treatment schedule.

After a 2-week adaptation period, rabbits were randomly assigned to five equal groups: control (normal) group fed on standard a diet, HCD control group fed on HCD (1\% cholesterol), and three groups fed on HCD and treated with $P$. eldarica nut in three different doses (50, 100 and $200 \mathrm{mg} / \mathrm{kg} /$ day). The extract in the dosages of 50,100, $200 \mathrm{mg}$ was mixed with little amount of rabbit pellets and fed orally one hour before feeding. The whole experiment lasted 8 weeks. Upon termination of the study biochemical analysis of serum lipids and pathological evaluation of aortas were performed.

\section{Biochemical analysis}

At the end of the study, the overnight fasting blood sample was taken from marginal ear veins for lipid analysis. Fasting blood cholesterol (Cho) LDL, HDL and triglyceride (TG) levels in sera were measured using enzyme assay kits (Pars Azmun Co., Iran).

\section{Pathological analysis}

At the end of the study, rabbits were killed by chloroform (overdose) and their aortas were separated up to diaphragm. The aortas were then divided into the proximal, middle, and distal segments. The aortic specimens were dehydrated in a graded series of alcohol xylene and embedded in paraffin for light microscopic examination. From each paraffin block, four sections of $4 \mathrm{~mm}^{2}$ were cut and stained with hematoxylin and eosin. All sections were evaluated microscopically for fatty streak, foam cells, extracellular lipid core, as atheromatous plaque elements. The degree of vascular injury and atherosclerosis was 
Table 1 Percent of polyphenols in P. eldarica nut mean \pm SD [16]

\begin{tabular}{lr}
\hline Polyphenols & Percent \\
\hline Catechin & $10.1 \pm 0.18$ \\
Epicatechin & $10.3 \pm 0.18$ \\
Gallic acid & $1.6 \pm 0.09$ \\
P. coumaric acid & $1.4 \pm 0.12$ \\
Ferullic acid & $1.7 \pm 0.21$ \\
O. coumaric acid & $0.12 \pm 0.02$ \\
Tyrosol & $29.1 \pm 0.08$ \\
Dimers of catechin and epicatechin & $7.5 \pm 1.06$ \\
Unknown & $38.18 \pm 0.28$ \\
Total phenols (ppm) & $483 \pm 27$ \\
\hline
\end{tabular}

quantitatively measured based on lesion area (on scale of $\mathrm{mm}^{2}$ ) with use of a color image analyzer (E200; Nikon, Tokyo, Japan) [17]. Both the surgeon and the pathologist were blinded to the control and experiment groups.

\section{Statistical analysis}

All values are expressed as means \pm SE. Data were analyzed by one way ANOVA, and all differences were inspected by Duncan's multiple test. Differences were considered to be significant at $p<0.05$.

\section{Results}

The polyphenol content of the P. eldarica nut is presented in Table 1 . Considering this method more than 8 polyphenols were identified in $P$. eldarica nut in which catechin, epicatechin and tyrosol were highest in concentration.
Results show that feeding the rabbits for 8 weeks with HCD leads to a significant increase in their blood serum total cholesterol, LDL-C and to a lesser extent in TG levels. Results indicate that serum total cholesterol and LDL-C levels significantly decrease in the groups treated with $200 \mathrm{mg} / \mathrm{kg} /$ day and $100 \mathrm{mg} / \mathrm{kg} /$ day of $P$. eldarica compared to the control group; although it is of note that all of the aortic samples from HCD-fed rabbits showed some degree of atherogenesis and none of them were normal. There were no significant changes in fasting blood TG and HDL-C levels in P. eldarica treated groups compared to control group (Table 2) (Fig. 1).

Morphological changes of the aortic wall atherosclerotic involvement are shown in Fig. 1. The aortic wall area percent in groups treated with $200 \mathrm{mg} / \mathrm{kg} /$ day and $100 \mathrm{mg} / \mathrm{kg} /$ day $P$. eldarica nut decreased significantly compared to the control group (Table 2).

\section{Discussion}

The results suggest that $P$. eldarica nut extract reduced total cholesterol, LDL-C and extent of aortic atherosclerotic involvement in hypercholesterolemic rabbits. The mechanism underlying inhibition of aortic atherosclerotic progression by $P$. eldarica nut extract may not be solely due to its lipid lowering effect, as the levels of serum total cholesterol and LDL-C were remarkably higher in cholesterol-fed rabbits than in normal ones. Other mechanisms may also play a role for such effect. Increases in serum cholesterol and LDL-C and consequent oxidation of LDL-C are essential steps for development of atherosclerotic plaques [2]. In fact formation of oxidatively-modified LDL-C is the first step of atherogenesis in so-called "oxidation hypothesis" [17].

Table 2 The fasting blood parameters and aortic wall area percent $\left(\mathrm{mm}^{2}\right)$ after 8 weeks of high cholesterol diet (HCD) fed rabbits treated with $P$. eldarica nut extract at dosages of 50, 100, $200 \mathrm{mg} / \mathrm{kg}$ compared with high control HCD fed rabbits (mean \pm SD)

\begin{tabular}{|c|c|c|c|c|c|c|}
\hline Groups & $\begin{array}{l}\text { Triglyceride } \\
(\mathrm{mg} / \mathrm{dl})\end{array}$ & $\begin{array}{l}\text { Cholesterol } \\
(\mathrm{mg} / \mathrm{dl})\end{array}$ & LDL (mg/dl) & $\begin{array}{l}\mathrm{HDL}(\mathrm{mg} / \\
\mathrm{dl})\end{array}$ & $\begin{array}{l}\text { Aortic wall area percent } \\
\left(\mathrm{mm}^{2}\right)\end{array}$ & $\begin{array}{l}\text { Percent of aortic wall area } \\
\text { changes }\end{array}$ \\
\hline Control (normal) & $60.4 \pm 15.8$ & $31.4 \pm 4.5$ & $9.2 \pm 4.7$ & $13.2 \pm 3.2$ & $0.247 \pm 0.032$ & \\
\hline \multirow[t]{2}{*}{ Control (HCD) } & $91.2 \pm 48.9$ & $1545.6 \pm 510.6$ & $1060.6 \pm 360.5$ & $113.4 \pm 55.8$ & $0.296 \pm 0.049$ & $\begin{array}{l}16.55 \uparrow \text { Compared with control } \\
\text { (normal) }\end{array}$ \\
\hline & $P=0.218^{*}$ & $P=0.003^{*}$ & $P=0.016^{*}$ & $P=0.003^{*}$ & $P=0.005^{*}$ & \\
\hline \multirow[t]{2}{*}{$\begin{array}{l}\text { P. eldarica nut extract } \\
50 \mathrm{mg} / \mathrm{kg}\end{array}$} & $93.6 \pm 31.2$ & $1253.0 \pm 578.0$ & $834.4 \pm 201.2$ & $87.6 \pm 17.7$ & $0.276 \pm 0.048$ & $\begin{array}{l}6.76 \downarrow \text { compared with control } \\
\text { (HCD) }\end{array}$ \\
\hline & $P=0.929^{* *}$ & $P=0.421^{* *}$ & $P=0.544^{* *}$ & $P=0.351^{* *}$ & $P=0.350^{* *}$ & \\
\hline \multirow[t]{2}{*}{$\begin{array}{l}\text { P. eldarica nut extract } \\
100 \mathrm{mg} / \mathrm{kg}\end{array}$} & $102.2 \pm 37.7$ & $834.4 \pm 201.2$ & $552.4 \pm 158.2$ & $90.2 \pm 15.9$ & $0.261 \pm 0.038$ & $\begin{array}{l}11.83 \downarrow \text { compared with control } \\
\text { (HCD) }\end{array}$ \\
\hline & $P=0.700^{* *}$ & $P=0.020^{* *}$ & $P=0.034^{* *}$ & $P=0.410^{* *}$ & $P=0.048^{* *}$ & \\
\hline \multirow[t]{2}{*}{$\begin{array}{l}\text { P. eldarica nut extract } \\
200 \mathrm{mg} / \mathrm{kg}\end{array}$} & $108.8 \pm 28.0$ & $710.4 \pm 448.0$ & $438.4 \pm 292.2$ & $99.4 \pm 11.8$ & $0.259 \pm 0.042$ & $\begin{array}{l}12.50 \downarrow \text { compared with control } \\
\text { (HCD) }\end{array}$ \\
\hline & $P=0.505^{* *}$ & $P=0.025^{* *}$ & $P=0.020^{* *}$ & $P=0.47^{* *} 0$ & $P=0.032^{* *}$ & \\
\hline
\end{tabular}

$P<0.05$ was considered as statistically significant

${ }^{*}$ compared with control (normal) group

${ }^{* *}$ compared with control (HCD) group 

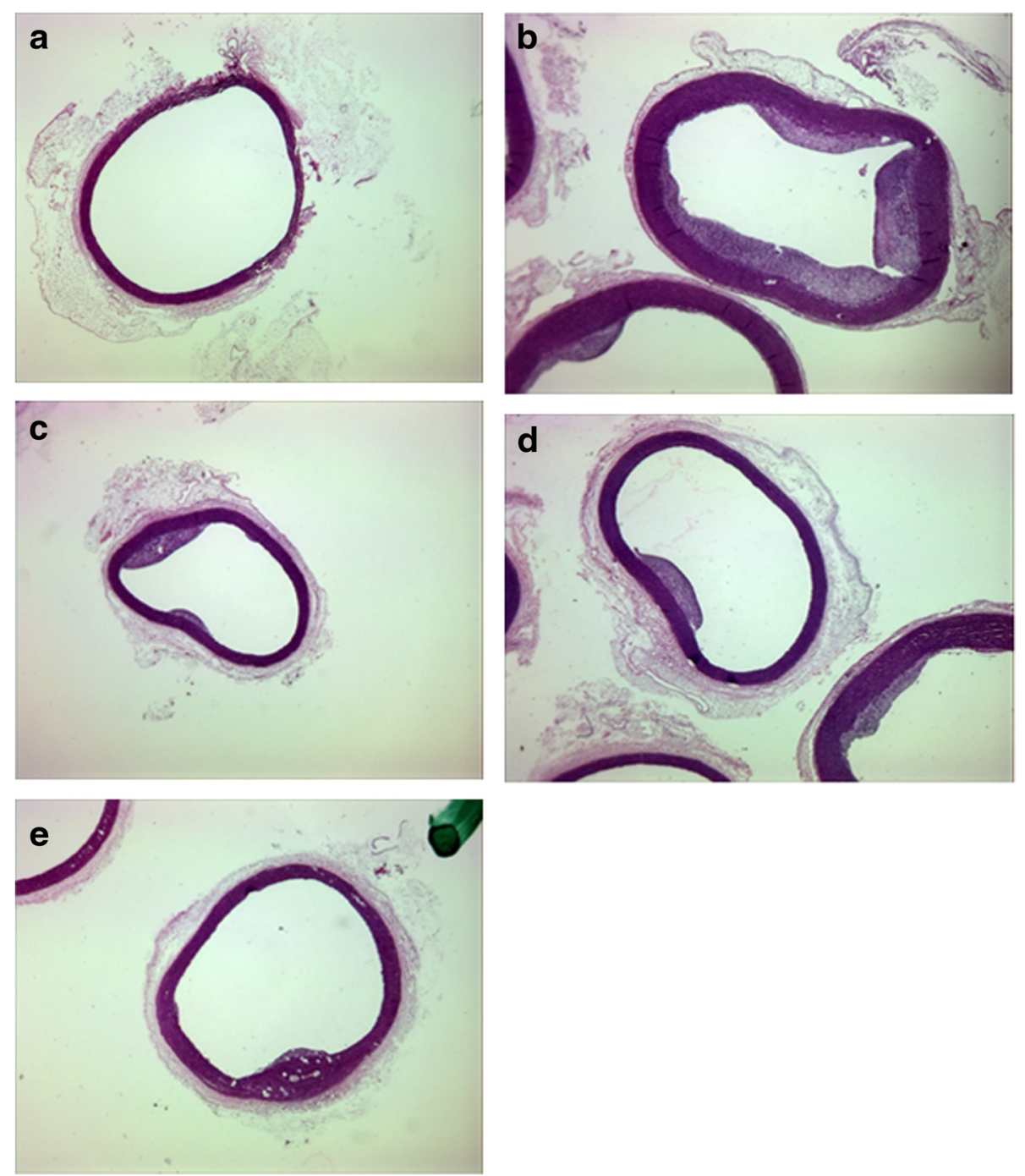

Fig. 1 Morphological changes of the aortic wall atherosclerotic involvement. a Normal rabbits fed on standard laboratory diet, b Rabbits fed on HCD; c Rabbits fed on HCD and treated with $50 \mathrm{mg} / \mathrm{kg}$ of $P$. eldarica; d Rabbits fed on HCD and treated with $100 \mathrm{mg} / \mathrm{kg}$ of $P$. eldarica; e Rabbits fed on HCD and treated with $200 \mathrm{mg} / \mathrm{kg}$ of $P$. eldarica

Moreover it has been shown that susceptibility of LDL$\mathrm{C}$ to oxidation independently correlates with the extent of atherosclerosis [18]. It is now established that inhibition of oxidative stress and lipid oxidation could have beneficial effects on regression of atherogenesis [19]. P. eldarica nuts contain high concentrations of polyphenols and flavonoids (Table 1) [10]. Several data suggested that, flavonoids improve dyslipidemia, inhibit lowdensity lipoprotein cholesterol oxidation and protect vascular endothelium against oxidative damage [20-22]. Furthermore, catechin and epicatechin which are found in high concentrations in P. eldarica nuts are also main chemical constituent of other Pinus species barks such as French matitime pine bark extract (pycnogenol) [23]. Several studies have shown the beneficial effects of pycnogenol for health to be mainly due to its antioxidant properties and consequent excellent free radical scavenging function [24-26]. In addition other components such as tyrosol with antioxidant properties which are present in high concentrations in P. eldarica nuts may directly or indirectly influence lipoprotein and cellular metabolism against atherogenesis [10, 27].

On the other hand, the observed anti-atherogenic effects of $P$. eldarica nut in the rabbits may also be in part due to appreciable amounts of essential oils such as $\alpha$ pinene, $\beta$-pinene and $\beta$-caryophyllene present in this nut [9]. The antioxidant properties of $\alpha$-pinene, $\beta$-pinene and $\beta$-caryophyllene are reported in other studies [28]. Of note the limitations of this study were lack of determination of the essential oil components and antioxidant properties of $P$. eldarica nut extract. To our knowledge this is the first trial on the anti-atherosclerotic and 
hypolipidemic effects of $P$. eldarica extracts on hypercholesterolemic rabbits. In a similar study we also have recently shown the beneficial effects of Pinus eldarica nut extract on blood glucose and cholesterol levels in hypercholesterolemic alloxan-induced diabetic rats [29]. As $P$. eldarica nuts are usually safe and used as food, further investigation of their clinical efficacy in the treatment of hypercholesterolemia is suggested.

\section{Competing interests}

The authors declare that they have no competing interests.

\section{Authors' contributions}

HFH performed the field trial and preparation of the manuscript, MSA performed the pathological analysis, YTk contributed in preparing the research proposal, SR prepared aortic specimens for pathological analysis, FS performed the statistical analysis, SMA contributed in the field trial and laboratory analysis, HF was the principle investigator who conceived the idea and prepared the research proposal and helped in the preparation of the manuscript. All authors read and approved the final manuscript.

\section{Acknowledgements}

This research was supported by a grant from the Endocrinology and Metabolism Research Institute, Tehran University of Medical Sciences Tehran, Iran and the Institute of Medicinal Plants (ACECR), Karaj.

\section{Author details}

${ }^{1}$ Medicinal Plants Research Center, Institute of Medicinal Plants, ACECR, Karaj, Iran. ${ }^{2}$ Clinical and Surgical Pathology Department Tehran Heart Center, Tehran University of Medical Sciences, Tehran, Iran. ${ }^{3}$ Endocrinology and Metabolism Research Center, Endocrinology and Metabolism Clinical Sciences Institute, Tehran University of Medical Sciences, Tehran, Iran. ${ }^{4}$ Experimental Research Center, Tehran Heart Center, Tehran University of Medical Sciences, Tehran, Iran. ${ }^{5}$ Elderly Health Research Center, Endocrinology and Metabolism Population Sciences Institute, Tehran University of Medical Sciences, 4th floor, No 4, Ostad Nejatollahi Street, Engelab Avenue, Tehran, Iran.

Received: 30 December 2014 Accepted: 18 May 2015

Published online: 09 June 2015

\section{References}

1. Finegold JA, Asaria P, Francis DP. Mortality from ischaemic heart disease by country, region, and age: statistics from World Health Organisation and United Nations. Int J Cardiol. 2012;168(2):934-45.

2. Badimon L, Vilahur G. LDL-cholesterol versus $\mathrm{HDL}$-cholesterol in the atherosclerotic plaque: inflammatory resolution versus thrombotic chaos. Ann N Y Acad Sci. 2012;1254:18-32.

3. Stocker R, Keaney Jr JF. Role of oxidative modifications in atherosclerosis. Physiol Rev. 2004:84(4):1381-478.

4. Chen K, Keaney Jr JF. Evolving concepts of oxidative stress and reactive oxygen species in cardiovascular disease. Curr Atheroscler Rep. 2012;14(5):476-83

5. Zargary A. Medicinal plants. 5th ed. Tehran: Tehran University Press; 1996. p. 9-12.

6. Mozaffarian W. Tree and shrubs of Iran. 1st ed. Tehran Iran: Farhang Moaser Press; 1983. p. 563-5.

7. Mamedov N, Craker LE. Medicinal plants used for the treatment of bronchial asthma in Russia and Central Asia. J Herbs Spices Med Plants. 2001;8:91-117.

8. Mamedov N, Gardner Z, Craker LE. Medicinal plants used in Russia and Central Asia for the treatment of selected skin conditions. J Herbs Spices Med Plants. 2005;11:191-222.

9. Afsharypour S, Sanaty F. Essential oil constituents of leaves and fruits of Pinus eldarica Medw. J Essent Oil Res. 2005;17:327-8.

10. Sadeghi Afjeh M, Fallah Huseini H, Tajalizadekhoob Y, Mirarefin M, Sharifi F, Taheri $E$, et al. Determination of phenolic compounds in Pinus eldarica by HPLC. J Med Plant Res. 2014;49:23-33.

11. Pandey KB, Rizvi SI. Plant polyphenols as dietary antioxidants in human health and disease. Oxid Med Cell Longev. 2009;2(5):270-8.
12. Pandey KB, Rizvi SI. Current understanding of dietary polyphenols and their role in health and disease. Curr Nutr Food Sci. 2009;5(4):249-63.

13. Tavakoli R, Mohadjerani M, Hosseinzadeh R, Tajbakhsh M, Naqinezhad A. Essential-oil and fatty-acid composition, and antioxidant activity of extracts of Ficaria kochii. Chem Biodivers. 2012;9(12):2732-41.

14. Causey JL. Korean pine nut fatty acids induce satiety-producing hormone release in overweight human volunteers, American Chemical Society National Meeting \& Exposition. 2006. p. 26-30.

15. Dogan S, Diken ME, Dogan M. Antioxidant, phenolic and protein contents of some medicinal plants. J Med Plant Res. 2010;4:2566-73.

16. Sadeghi Afjeh M, Fallah Huseini H, Tajallizadekhoob Y, Mirarefin M, Taheri E, Saeednia S, et al. Determination of phenolic compounds in Pinus Eldarica by HPLC. J Med Plant Res. 2014;13(49):22-33.

17. Kumar V, Abbas AK, Fausto N. Pathologic basis of disease. 7th ed. Philadelphia: Saunders; 2005. p. 25-6.

18. Regnström J, Nilsson J, Tornvall P, Landou C, Hamsten A. Susceptibility to low- density-lipoprotein oxidation and coronary atherosclerosis in man. Lancet. 1992;339:1183-6.

19. Heinecke JW. Oxidants and antioxidants in the pathogenesis of atherosclerosis: implications for the oxidised low density lipoprotein hypothesis. Atheroscler. 1998;141:1-15.

20. Loke WM, Proudfoot JM, Hodgson JM, McKinley AJ, Hime N, Magat M, et al. Specific dietary polyphenols attenuate atherosclerosis in apolipoprotein E-knockout mice by alleviating inflammation and endothelial dysfunction. Arterioscler Thromb Vasc Biol. 2010;30(4):749-57.

21. Martin S, Andriantsitohaina R. Cellular mechanism of vasculo-protection induced by polyphenols on the endothelium. Ann Cardiol Angeiol (Paris). 2002;51(6):304-15.

22. Mulvihill EE, Huff MW. Antiatherogenic properties of flavonoids: implications for cardiovascular health. Can J Cardiol. 2010;26:17A-21.

23. Yesli-Celiktas O, Ganzera M, Akgun I, Sevimli C, Korkmaz KS, Bedir E. Determination of polyphenolic constituents and biological activities of bark extracts from different Pinus species. J Sci Food Agric. 2009;89(8):1339-45.

24. Rohdewald P. A review of the French matitime pine bark extract (Pycnogenol), a herbal medication with a diverse pharmacology. Int J Clin Pharmacol Ther. 2002;40:158-68.

25. Sato M, Yamada Y, Matsuoka H, Nakashima S, Kamiya T, Ikeguchi M, et al. Dietary pine bark extract inhibit atherosclerotic lesion development in male Apo-E-deficient mice by lowering the serum cholesterol level. Biosci Biotechnol Biochem. 2009;73:1314-7.

26. Maritim A, Dene BA, Sanders RA, Watkins JB. Effects of Pycnogenol treatment on oxidative stress in streptozotocin-induced diabetic rats. $J$ Biochem Mol Toxicol. 2003;17:193-9.

27. Giovannini C, Straface E, Modesti D, Coni E, Cantafora A, De Vincenzi M, et al. Tyrosol, the major olive oil biophenol, protects against oxidized-LDLinduced injury in Caco-2 cells. J Nutr. 1999;129(7):1269-77.

28. Miguel MG. Antioxidant and anti-inflammatory activities of essential oils: a short review. Molecules. 2010;15(12):9252-87.

29. Fallah Huseini H, Mehrzadi S, Ghaznavi H, Tajallizadehkhoob Y, Fakhrzadeh $H$. Effects of pinus eldarica medw: nut extract on blood glucose and cholesterol levels in hypercholesterolemic alloxan-induced diabetic rats. J Med Plant Res. 2013;1(45):68-74.

\section{Submit your next manuscript to BioMed Central and take full advantage of:}

- Convenient online submission

- Thorough peer review

- No space constraints or color figure charges

- Immediate publication on acceptance

- Inclusion in PubMed, CAS, Scopus and Google Scholar

- Research which is freely available for redistribution 